\title{
Modelos para el uso de la fotografía en la docencia: el proyecto Imaginando
}

\author{
Models for using photography in teaching: the Imaginando (Imagining) project
}

\author{
Juan Miguel Sánchez Vigil (1), María Olivera Zaldua (2), Juan Carlos Marcos Recio (3)
}

(1) Departamento de Biblioteconomía y Documentación, Facultad de Ciencias de la Documentación de la UCM, C/Santísima Trinidad 37, 28010 Madrid, jmvigil@ucm.es. (2) molivera@ucm.es (3) Sección Departamental de Biblioteconomía y Documentación, Facultad de Ciencias de la Información, Av. Ciudad Universitaria s/n, 280409 Madrid, jmarcos@ucm.es

\begin{abstract}
Resumen
El uso de la fotografía en la investigación y la docencia es habitual desde la segunda mitad del siglo XIX, $\mathrm{y}$ los valores de la imagen se justifican con las colecciones que nos han legado intelectuales y profesores. De acuerdo con las directrices del Espacio Europeo de Educación Superior, la motivación de los alumnos y su implicación en los procesos de aprendizaje es uno de los objetivos más importantes. Teniendo en cuenta los dos aspectos anteriores se ha desarrollado el proyecto "Imaginando" dentro del programa de Innovación Docente de la Universidad Complutense, cuyo objetivo en la creación de un banco de imágenes fotográficas para uso y aplicación de docentes, investigadores y alumnos. Se presentan en este artículo a la comunidad científica el planteamiento, desarrollo y resultados del mismo. La participación fue de 258 alumnos de 15 asignaturas y se generaron 2384 fotos para 92 conceptos entre 2011 y 2014.
\end{abstract}

Palabras clave: Docencia. Fotografía. Innovación docente. Documentación fotográfica. Espacio Europeo de Educación Superior. Proyecto Imaginando.

\section{Introdución}

La fotografía forma parte de nuestra cultura y condiciona nuestras acciones. Su valor artístico, informativo y documental, así como su condición de artefacto (objeto hecho con arte) le confieren cualidades especiales, de ahí que haya sido empleada en la investigación, la formación y la docencia desde su presentación oficial en París en el año 1839 por Louis Jacques Mandé Daguerre.

Sin embargo, en lo que se refiere a la enseñanza, es significativo que tras casi dos siglos de historia continúe siendo una de las materias con escasa presencia en los planes de estudio, tanto en la enseñanza secundaria como en la superior, y que se la considere generalmente un elemento auxiliar cuando debería ser estudiada desde numerosos aspectos gracias a su transversalidad, así como a su uso y aplicación en materias como la medicina, el arte, los medios de comunicación, la historia, la física, etc.

\begin{abstract}
The use of photography in research and teaching has been customary as of the second half of the 19th century and the importance of the pictures are justified with the collections which intellectuals and professionals have bequeathed to us. According to the guidelines of the European Department of Higher Education, the students' motivation and their involvement in the learning processes is one of the most important goals. According to it, the "Imaginando" project has been developed as part of the Innovating Teaching Program of Madrid's Complutense University, whose objective is to create a bank of photographs for use and aplicación by teachers, researchers and students. The approach, development and results of this program are presented to the scientific community in this article. A total of 258 students from 15 classes participated, with 2,384 photographs corresponding to 92 different subjects between 2011 and 2014 .
\end{abstract}

Keywords: Teaching. Photography. Teaching innovation. Photographic documentation. European Higher Education Area. Imaginando Project.

Por ello nos planteamos analizar el uso de la foto en la docencia, concretamente en la universidad española. En ese contexto surgió la idea de generar un banco de imágenes creado por los propios estudiantes en función de sus intereses y obviamente aplicable a la docencia para beneficio de profesores, investigadores y alumnos. Ese fue el origen del proyecto que se ha denomino "Imaginando", y que ha sido desarrollado durante tres años (2011-2014) en la Facultad de Ciencias de la Documentación de la Universidad Complutense de Madrid, coordinado por Juan Miguel Sánchez Vigil y en el que han participado María Olivera Zaldua, Juan Carlos Marcos Recio, Antonia Salvador Benítez y Federico Ayala Sorennsen, profesores especialistas en documentación informativa, fotográfica, audiovisual, cinematográfica y publicitaria. Siguiendo las pautas del Espacio Europeo de Educación Superior, se diseñaron los modelos de actuación. Se tuvieron en cuenta dos premisas como punto de partida: la motivación de los 
estudiantes para despertar su interés y conseguir su activa participación, y la calidad del producto resultante (colección de fotos del banco de imágenes), de tal forma que su utilidad fuera real para la comunidad académica y para la investigación. En los tres años de actuación se consiguieron ambos objetivos, con la participación de 258 estudiantes y un banco de imágenes compuesto por más de 2.000 fotografías listas para su uso.

\section{De la fotografía y la docencia}

La fotografía está presente en la docencia desde dos vertientes: la enseñanza y el uso. Planteamos estas dos cuestiones que, pareciendo antagónicas, no lo son: por una parte su enseñanza y por otra el empleo en la tarea a realizar, que finalmente entroncan en el concepto global de docencia.Con carácter general, basta realizar una búsqueda en las bases de datos ERIC o Science Direct para observar que la foto ha sido aplicada a la docencia en diferentes materias fuera de nuestro país (lengua inglesa: Britsch, 2010; matemáticas: Munakata y Vaidya, 2013; documentación: Springborg, 2013). En España también ha sido y es habitual su uso en la docencia e investigación por los intelectuales, desde los clásicos, entre ellos Santiago Ramón y Cajal (Ciencias), Ramón Menéndez Pidal (Historia), Enrique Lafuente Ferrari o Diego Angulo İñiguez (Arte), hasta los contemporáneos. No es un descubrimiento indicar como los docentes emplean recursos y materiales de las redes sociales o de otra fuentes de internet, por otra parte sujetos a derechos y sometidos a las pautas que marcan las políticas de actuación de los centros o instituciones de procedencia.

Los clásicos, a quienes deberíamos llamar sabios, formaron sus propias colecciones y las legaron para su conservación y estudio a instituciones de prestigio. Así, la colección Lafuente Ferrari (Casajús, Diéguez y Pena, 2008) se conserva en la Biblioteca de la Universidad Complutense y la de Diego Angulo Íñiguez en el Consejo Superior de Investiaciones Científicas. Esta última ha sido analizada y puesta en valor dentro del proyecto de investigación titulado "Imágenes del Nuevo Mundo: el patrimonio artístico portugués e iberoamericano a través del legado fotográfico de Diego Angulo Íñiguez al CSIC", bajo la dirección del profesor Wifredo Rincón García (2012).

Sin embargo, el análisis de tales usos y aplicaciones apenas se ha realizado. Tan solo se apunta en monografías históricas (Sánchez Vigil, 2001), en artículos específicos sobre recursos de instituciones, como es el caso de la
Universidad Carlos III (Moreiro, 2014) o en valoraciones más generales sobre educación y aprendizaje de la información y documentación (García Marco, 2013).

En cuanto a la enseñanza, el Espacio Europeo de Educación Superior ha propiciado cambios importantes, si bien todavía mejorables, ya que siguen siendo las enseñanzas no oficiales las que se encargan de los estudios sobre la materia: títulos propios o de expertos, seminarios, cursos, etc. Debemos aclarar que no nos referimos a la calidad sino a su cualidad, ya que muchos de estos títulos alcanzan el nivel de excelencia por sus programas y profesorado, como es el caso del título propio "Máster en Fotografía, Arte y Técnica" de la Universitat Politècnica de València.

Por último, señalaremos que en la investigación sobre temas relacionados con la fotografía (trabajos de fin de máster, trabajos de fin de grado o tesis doctorales), se ha detectado un considerable aumento (Sánchez Vigil, Marcos Recio y Olivera Zaldua, 2014) tras la creación de nuevos másteres. Citaremos dos ejemplos por la producción de trabajos: el "Máster de Gestión de la Documentación, Bibliotecas y Archivos (especialidad en Medios de Comunicación)" de la Facultad de Ciencias de la Documentación, o el "Máster en Patrimonio Audiovisual: Historia, Recuperación y Gestión", impartido en la Facultad de Ciencias de la Información, ambos de la Universidad Complutense de Madrid.

\section{Objeto y método}

El objeto, como se ha indicado, fue la creación de un banco de imágenes fotográficas, realizadas por los estudiantes, como apoyo a la docencia e investigación, abierto al uso de profesores, investigadores y alumnos, libre de derechos para utilización no comercial y susceptible de ser ampliado. Uno de los primeros objetivos fue el desarrollo de la imaginación del alumno, del que deriva el nombre del proyecto (Imaginando), basado en el consenso de los conceptos a fotografiar, la planificación de las imágenes a realizar, y las habilidades para asociar la fotografía a dichos conceptos, de forma que se representaran los contenidos de los módulos, lecciones o temas vinculados a un conocimiento concreto. Los objetivos específicos fueron:

1. Uso y aplicación de la fotografía en el proceso de aprendizaje, y en el aula, plasmando las ideas en imágenes.

2. Asimilar los contenidos teóricos sobre determinadas materias o temas mediante la fotografía y su representación. 
3. Aprendizaje de la fotografía desde los aspectos técnico, artístico y sociocultural, destacando sus valores en los diferentes campos.

4. Favorecer la relación entre los alumnos mediante el intercambio de experiencias antes, durante y después de la creación de la imagen, debatiendo en el aula la elección y la idoneidad del tema para cada caso.

5. Creación de un banco de imágenes fotográficas asociadas a ideas, y puesto a disposición del profesorado, los investigadores y los estudiantes para su uso libre de derechos

6. Documentación de todas las fotografías producidas durante el proceso de realización; y valoración de los contenidos para usos distintos al pensado inicialmente.

7. Difusión de las experiencias mediante la muestra pública de las mejores imágenes seleccionadas por los autores; y creación y montaje de exposiciones para su exhibición en sala y online.

El método de trabajo se desarrolló en diez puntos: 1) selección de las asignaturas en las que aplicar el proyecto; 2) diseño de un cronograma de trabajo, con periodicidad semanal; 3) selección de un concepto (palabra clave o descriptor), relacionado con los temas tratados en las clases; 4) definición de las características técnicas de la imagen; 5) creación de las fotografías por los alumnos, de forma que se representara el tema tratado; 6) diseño de una ficha para la documentación de las imágenes tomando como modelo las ISAD-G para descripción de fotografías (Figura 1); 7) fase de documentación con el análisis de contenido de cada imagen; 8) presentación de la fotografía en baja resolución junto a la ficha documental; 9) descarte de las imágenes no ajustadas a los protocolos de calidad; 10) fase de difusión mediante el diseño de exposición y desarrollo de la misma.

En cuanto a la metodología seguida para la presentación de los resultados se procedió en primer lugar a la cuantificación de las imágenes, poniendo en valor la participación de los alumnos por asignaturas; en segundo término, se comprobó la originalidad de las imágenes y la cesión de derechos de las mismas; $y$, por último, se debatió sobre la cualidad y calidad de los contenidos, seleccionando las ilustraciones como muestra del trabajo realizado. Se trabajó semanalmente con este orden: selección del concepto, realización de la fotografía, análisis de la misma y entrega de la ficha con la información recopilada y la cesión de derechos para su uso no comercial. Las imágenes se realizaron en alta resolución (mínimo de $1 \mathrm{MB}$ ).

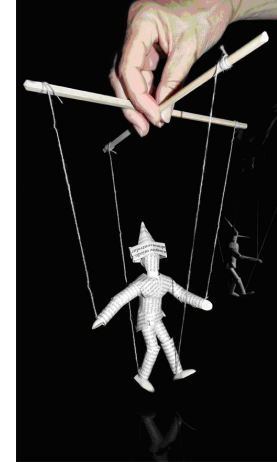

№ Identificador (Número+iniciales nombre y apellidos-Término o Concepto)

\begin{tabular}{|c|}
\hline 001TMB-MEDIOS DE COMUNICACIÓN \\
\hline Autor (Apellidos y Nombre del alumno) \\
\hline Melgar Bautista, Teresa \\
\hline Título (elegido por el autor) \\
\hline Marionetas de la verdad \\
\hline Fecha (fecha de la fotografía) \\
\hline $12 / 10 / 2011$ \\
\hline Lugar (lugar en que se realizó) \\
\hline Majadahonda \\
\hline Resumen (resumen del contenido) \\
\hline $\begin{array}{l}\text { Marioneta de hilos, hecha de papel de periódico, sujeta por una } \\
\text { mano, y con un reflejo distinto en el fondo }\end{array}$ \\
\hline Descriptores Onomásticos (nombres de personas físicas y jurídicas) \\
\hline Pinocho; Melgar Bautista, Teresa \\
\hline $\begin{array}{l}\text { Descriptores Geográficos (nombres de lugares, accidentes geográfi- } \\
\text { cos, etc.) }\end{array}$ \\
\hline Majadahonda; Madrid; España \\
\hline Descriptores Cronológicos (día, mes, año, siglo) \\
\hline 12/10/2011; 2011; S. XXI \\
\hline Descriptores Temáticos (materias y temas) \\
\hline $\begin{array}{l}\text { Mano; marionetas; títeres; periódicos; papel de periódico; hilos; } \\
\text { marioneta de hilos; medios de comunicación; manipulación; control; } \\
\text { poder; información; influencia; oscuridad; teatro; guiñol; opinión } \\
\text { pública; control de masas }\end{array}$ \\
\hline
\end{tabular}

Pie de foto informativo (texto breve y conciso sobre el contenido de la imagen)

Marioneta de hilos, hecha de papel de periódico, sobre fondo negro. El reflejo de la marioneta representa a Pinocho/Teresa Melgar Bautista

Pie de foto literario (texto de 4-6 líneas explicativas de la imagen y creativo)

La manipulación, tanto económica como política, de los medios de comunicación (uno de los poderes fácticos de la sociedad), trastocan la verdad para que se adapte a sus intereses. Aunque aparenten seriedad y rigor informativo, los se asemejan a un espectáculo en el que la verdad se oculta tras las bambalinas / Teresa Melgar Bautista

El autor de la foto cede todos los derechos para su uso no comercial

Fdo.

Figura 1. Ficha de descripción y análisis documental

La información de las fichas fue contrastada y validada, conservando el documento impreso y el fichero digital con la firma del alumno como 
autor y responsable de la imagen. Las fichas sin firma anulan el uso de las fotografías en cuanto a su difusión o reproducción pública.

\section{Resultados}

Se presentan a continuación en varias tablas los resultados obtenidos, que consideramos excelentes tanto por la participación de los alumnos como por la cantidad y calidad de las fotografías. En los tres años de duración del proyecto (2011-2014) se han desarrollado tres fases correspondientes a tres cursos, con una participación de 258 autores (estudiantes) de 15 asignaturas. Se generaron 2.384 fotografías correspondientes a 92 términos relacionados con la docencia, con una media de 9,24 fotos por autor. Aunque el número de conceptos seleccionados por los alumnos, como se indica, fue de 92 , finalmente quedaron reducidos a 79 al coincidir los mismos términos en varios grupos de trabajo (Tablas I y II, y Figura 2).

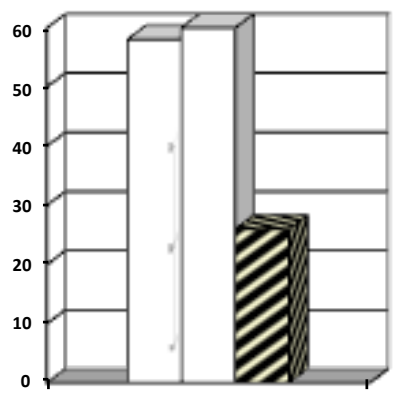

Términos

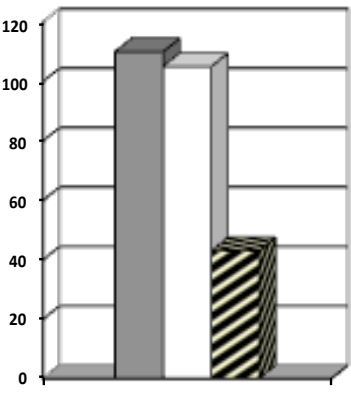

Autores

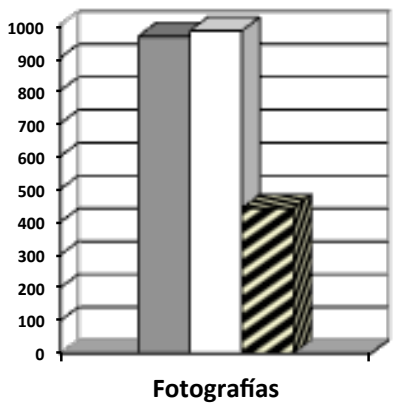

$\square$ 2011-2012

$\square$ 2012-2013

$\nabla 2013-2014$

Figura 2. Comparativa de términos, autores y fotografías

\begin{tabular}{lrrrr}
\hline Año & conceptos & asignaturas & autores & fotos \\
\hline $2011 / 2012$ & 48 & 5 & 110 & 964 \\
\hline $2012 / 2013$ & 34 & 7 & 105 & 981 \\
\hline $2013 / 2014$ & 10 & 3 & 43 & 439 \\
\hline Total & 92 & 15 & 258 & 2.384 \\
\hline
\end{tabular}

Tabla I. Conceptos, autores y fotografías realizadas (2001-2014)

\begin{tabular}{|c|c|c|c|}
\hline Conceptos & Fotos & Conceptos & Fotos \\
\hline Alegría & 8 & Indigencia & 12 \\
\hline Amistad & 66 & Infancia & 48 \\
\hline Amor & 65 & Información & 13 \\
\hline Archivo & 16 & Inmigración & 48 \\
\hline Arte & 74 & Libertad & 78 \\
\hline Biblioteca & 12 & Libro & 72 \\
\hline $\begin{array}{l}\text { Búsqueda de } \\
\text { información }\end{array}$ & 11 & Magia & 8 \\
\hline Calor & 7 & Mapa & 5 \\
\hline Ciencia & 68 & Medio Ambiente & 9 \\
\hline Cine & 71 & $\begin{array}{l}\text { Medios de } \\
\text { vomunicación }\end{array}$ & 74 \\
\hline Código & 8 & Miedo & 10 \\
\hline Colección & 21 & Miseria & 75 \\
\hline Comercio & 5 & Música & 8 \\
\hline Compromiso & 47 & Normalización & 19 \\
\hline Conciencia & 62 & Open Acess & 7 \\
\hline Conocimiento & 7 & Organicidad & 11 \\
\hline Consumo & 15 & Original & 10 \\
\hline Contaminación & 9 & Peligro & 8 \\
\hline Contenido & 7 & Persuasión & 9 \\
\hline Contexto & 11 & Poder & 8 \\
\hline Creatividad & 10 & Política & 79 \\
\hline Deporte & 71 & Prima de Riesgo & 9 \\
\hline Depresión & 13 & Primavera & 10 \\
\hline Deseo & 60 & Reciclar & 52 \\
\hline Documentación & 67 & Redes Sociales & 9 \\
\hline Documento & 10 & Riesgo & 46 \\
\hline Economía & 9 & Ruido & 8 \\
\hline Educación & 79 & Sexo & 77 \\
\hline Estrategia & 9 & Silencio & 8 \\
\hline Estrés & 76 & Solidaridad & 64 \\
\hline Estudio de mercado & 10 & Tecnología & 15 \\
\hline Exilio & 37 & Tesis Doctoral & 4 \\
\hline Fondos de rescate & 7 & Tiempo & 65 \\
\hline Formación & 48 & Titularidad & 9 \\
\hline Fotografía & 65 & Tráfico & 10 \\
\hline Fuente Primaria & 9 & Transporte & 9 \\
\hline $\begin{array}{l}\text { Fuentes } \\
\text { Información }\end{array}$ & 10 & Urbanismo & 13 \\
\hline Gente & 40 & Vacaciones & 39 \\
\hline Ilusión & 60 & Vejez & 34 \\
\hline Impacto & 10 & & \\
\hline Total & 2.384 & & \\
\hline
\end{tabular}

Tabla II. Relación de conceptos y número de fotografías

\subsection{Primera fase (2011-2012)}

En la primera fase del proyecto participaron 110 estudiantes (autores) de cinco asignaturas impartidas en la Facultad de Ciencias de la Documentación de la UCM en los estudios de Grado en Información y Documentación y Máster en Gestión de la Documentación. Se generaron 964 fotos, y la participación fue proporcional al número de alumnos por asignatura. El $74 \%$ de las imágenes fueron realizadas por los alumnos de los grupos A y B de Documentación Fotográfica (Tabla III). 


\begin{tabular}{lrr}
\hline Asignatura & Autores & Fotos \\
\hline Documentación Fotográfica Grupo A (Grado) & 48 & 426 \\
\hline Documentación Fotográfica Grupo B (Grado) & 28 & 290 \\
\hline Documentación Iconográfica (Máster) & 10 & 69 \\
\hline Fuentes generales de información (Grado) & 11 & 84 \\
\hline Gestión del Conocimiento (Máster) & 9 & 63 \\
\hline Documentación Multimedia (Máster) & 4 & 32 \\
\hline Total & 110 & 964 \\
\hline
\end{tabular}

Tabla III. Fotografías creadas

La media de fotos del grupo A de Documentación Fotográfica fue de 42 por tema, siendo el término "Política" el de mayor número de imágenes con 49, y el concepto "Deseo" el de menor con 28. En el grupo B, la media fue de 29 fotos, siendo la mayor respuesta creativa para los descriptores "Sexo" y "Deseo" con 32 y la menor para "Conciencia" con 21 (Tabla IV).

\begin{tabular}{lrr}
\hline Conceptos & Grupo A & Grupo B \\
\hline 001-Medios de Comunicación & 43 & 31 \\
\hline 002-Política & 49 & 30 \\
\hline 003-Sexo & 45 & 32 \\
\hline 004-Libertad & 47 & 31 \\
\hline 005-Miseria & 45 & 30 \\
\hline 006-Estrés & 45 & 31 \\
\hline 007-Ciencia & 42 & 26 \\
\hline 008-Conciencia & 41 & 21 \\
\hline 009-Documentación & 41 & 26 \\
\hline 010-Deseo & 28 & 32 \\
\hline Total & 426 & 290 \\
\hline
\end{tabular}

Tabla IV. Documentación Fotográfica: Fotos generadas (2011-2012)

En la asignatura Documentación Iconográfica del Máster en Gestión de la Documentación, especialidad en Medios de Comunicación, el proyecto dio como resultado 69 imágenes con 10 participantes que seleccionaron 8 conceptos distintos a los anteriores. La media de fotografías fue de 8 por tema, siendo "Indigencia" y "Biblioteca" los de más imágenes con 11, y "Magia" y "Poder" los de menos con 7 (Tabla V).

\begin{tabular}{lr}
\hline Conceptos & Fotos \\
\hline 001-Indigencia & 11 \\
\hline 002-Biblioteca & 11 \\
\hline 003-Medio Ambiente & 8 \\
\hline 004-Transporte & 8 \\
\hline 005-Magia & 7 \\
\hline 006-Poder & 7 \\
\hline 007-Miedo & 9 \\
\hline 008-Redes Sociales & 8 \\
\hline Total & 69
\end{tabular}

Tabla V. Documentación Iconográfica: Fotos generadas (2011-2012)
En la asignatura Fuentes Generales de Información (Grado) se ilustraron 10 términos sobre la materia con 84 fotos en total. Participaron 11 autores con una media de 8 imágenes por concepto, siendo "Normalización" y "Búsqueda de Información" los de mayores respuestas, y "Tesis Doctoral" el de menos con 4 (Tabla VI).

\begin{tabular}{|c|c|}
\hline Conceptos & Fotos \\
\hline 001-Búsqueda de Información & 11 \\
\hline 002-Fuentes de Información & 10 \\
\hline 003-Normalización & 11 \\
\hline 004-Tesis Doctoral & 4 \\
\hline 005-Fuente Primaria & 9 \\
\hline 006-Prima de Riesgo & 9 \\
\hline 007-Ruido & 8 \\
\hline 008-Silencio & 8 \\
\hline 009-Fondos de Rescate & 7 \\
\hline 010-Open Access & 7 \\
\hline Total & 84 \\
\hline
\end{tabular}

Tabla VI. Fuentes generales de información: Fotos generadas (2011-2012)

\begin{tabular}{lr}
\hline Conceptos & Fotos \\
\hline 001-Información & 10 \\
\hline 002-Documento & 7 \\
\hline 003-Educación & 7 \\
\hline 004-Economía & 6 \\
\hline 005-Música & 7 \\
\hline 006-Alegría & 6 \\
\hline 007-Peligro & 6 \\
\hline 008-Código & 6 \\
\hline $009-M a p a$ & 3 \\
\hline 010-Conocimiento & 5 \\
\hline Total & 63 \\
\hline
\end{tabular}

Tabla VII. Gestión del Conocimiento: Fotos generadas (2011-2012)

\begin{tabular}{|c|c|c|c|}
\hline Concepto & Fotos & Concepto & Fotos \\
\hline 001-Información & 3 & 001-Indigencia & 1 \\
\hline 002-Documento & 3 & 002-Biblioteca & 1 \\
\hline 003-Educación & 2 & 003-Medio Ambiente & 1 \\
\hline 004-Economía & 2 & 004-Transporte & 1 \\
\hline 005-Música & 2 & 005-Magia & 1 \\
\hline 006-Alegría & 2 & 006-Poder & 1 \\
\hline 007-Peligro & 2 & 007-Miedo & 1 \\
\hline 008-Código & 2 & 008-Redes Sociales & 1 \\
\hline 009-Мара & 3 & & 0 \\
\hline 010-Conocimiento & 3 & & 0 \\
\hline Total & 24 & Total & 8 \\
\hline
\end{tabular}

Tabla VIII. Documentación Multimedia: Fotos generadas (2011-2012)

En Gestión del Conocimiento (Máster) los conceptos seleccionados fueron más generales. Se obtuvieron 61 fotografías con una media de 6 por término, resultando los primeros "Informa- 
ción” con 10 y, "Documentación”, "Educación” y "Música", y el último en número de fotos "Mapa" con 3 (Tabla VII).

En la asignatura Documentación Multimedia (Máster) se consideraron los mismos conceptos que en Gestión del Conocimiento y Documentación Iconográfica, resultando 3 fotografías para los conceptos de la primera asignatura (Gestión) y una imagen para la segunda (Documentación Iconográfica), con un total de 32 fotografías (Tabla VIII).

\subsection{Segunda fase (2012-2013)}

En la segunda fase, correspondiente al curso 2012-2013, se generaron 981 fotografías. En este periodo, a modo de prueba y con el fin de observar la respuesta externa de alumnos no vinculados a la UCM, se planteó la colaboración de docentes de la Facultad de Comunicación de la Universidad de Brasilia, con resultado positivo (Tabla IX).

\begin{tabular}{lrr}
\hline Asignaturas & Autores & Fotos \\
\hline Documentación Fotográfica A (Grado) & 22 & 209 \\
\hline Documentación Fotográfica B (Grado) & 40 & 407 \\
\hline Documentación Iconográfica (Máster) & 15 & 127 \\
\hline Documentación Multimedia (Máster) & 10 & 67 \\
\hline $\begin{array}{l}\text { Documentación Publicitaria y de las RRPP } \\
\text { (Grado) }\end{array}$ & 6 & 58 \\
\hline Patrimonio Fotográfico (Máster) & 5 & 20 \\
\hline $\begin{array}{l}\text { Tópicos especiais em Organizaçao da } \\
\text { Informaçao. Acervos fotográficos (Grado) }\end{array}$ & 7 & 93 \\
\hline Total & 105 & 981 \\
\hline
\end{tabular}

Tabla IX. Fotografías creadas

\begin{tabular}{lrr}
\hline Conceptos & Grupo A & Grupo B \\
\hline 001-Libro & 21 & 38 \\
\hline 002-Cine & 22 & 37 \\
\hline 003-Arte & 21 & 42 \\
\hline 004-Solidaridad & 18 & 34 \\
\hline 005-Fotografía & 14 & 36 \\
\hline 006-Educación & 17 & 40 \\
\hline 007-Deporte & 20 & 39 \\
\hline 008-Tiempo & 19 & 35 \\
\hline 009-Amistad & 21 & 34 \\
\hline 010-Ilusión & 18 & 36 \\
\hline 011-Amor & 18 & 36 \\
\hline Total & 209 & 407 \\
\hline
\end{tabular}

Tabla X. Documentación Fotográfica: Fotografías generadas (2012-2013)

En la asignatura Documentación Fotográfica (Grado, Grupo A y B), se propusieron 11 temas de los que resultaron un total de 616 fotos. En el grupo A participaron 22 alumnos, con una media de 9,5 fotografías, y en el grupo $B$ fueron 40 los estudiantes, con una media de 10,2 fotos por alumno. Los conceptos con mayor número de fotos en el primero fueron "Cine" con 22 y "Amistad", "Libro" y "Arte" con 21, y en el segundo "Arte" con 42 y "Educación" con 40; en cuanto a los de menor resultado fueron "Fotografía" en el grupo A con 14, y "Amistad" en el B con 33 (Tabla X).

En la asignatura Documentación Iconográfica (Máster) se propusieron 11 términos de los que resultaron un total de 127 imágenes. Participaron 15 alumnos, con una media de 8,45 fotos por autor. El término con mayor número fue "Fotografía" con 15 aportaciones, y el de menos imágenes "llusión” con 6 (Tabla XI).

\begin{tabular}{lr}
\hline Concepto & Fotos \\
\hline 001-Libro & 13 \\
\hline 002-Cine & 12 \\
\hline 003-Arte & 11 \\
\hline 004-Solidaridad & 12 \\
\hline 005-Fotografía & 15 \\
\hline 006-Educación & 12 \\
\hline 007-Deporte & 12 \\
\hline 008-Tiempo & 11 \\
\hline 009-Amistad & 12 \\
\hline $010-$ Ilusión & 6 \\
\hline 011-Amor & 11 \\
\hline Total & 127 \\
\hline
\end{tabular}

Tabla XI. Documentación Iconográfica: Fotos generadas (2012-2013)

En Documentación Multimedia (Máster) se propusieron 9 términos de los que resultaron un total de 67 imágenes. Los autores fueron $10 \mathrm{y}$ por tanto la media de fotos por alumnos de 6,7. Los términos con mayor número de fotos fueron "Tecnología" y "Depresión" con 10 y con menor número "Comercio" y "Consumo" con 5 (Tabla XII).

\begin{tabular}{lr}
\hline Concepto & Fotos \\
\hline 001-Tecnología & 10 \\
\hline 002-Urbanismo & 9 \\
\hline 003-Depresión & 10 \\
\hline 004-Contaminación & 6 \\
\hline 005-Tráfico & 7 \\
\hline 006-Comercio & 5 \\
\hline 007-Consumo & 5 \\
\hline 008-Calor & 7 \\
\hline 009-Primavera & 8 \\
\hline Total & 67 \\
\hline
\end{tabular}

Tabla XII. Documentación Multimedia: Fotos generadas (2012-2013)

En la asignatura Documentación Publicitaria y de las Relaciones Públicas (Máster) se trabajó con 6 términos, de los que resultaron un total de 58 imágenes. Participaron 6 alumnos (Tabla 
XIII), con una media de 9,6 fotos por autor. En este caso prácticamente todos los términos tuvieron iguales resultados, entre 9 y 10 fotografías.

\begin{tabular}{lr}
\hline Concepto & Fotos \\
\hline 001-Persuasión & 9 \\
\hline 002-Estrategias & 9 \\
\hline $003-$ Impacto & 10 \\
\hline $004-C r e a t i v i d a d$ & 10 \\
\hline $005-C o n s u m o$ & 10 \\
\hline $006-$ Estudio de mercado & 10 \\
\hline Total & 58 \\
\hline
\end{tabular}

Tabla XIII. Documentación Publicitaria y de las Relaciones Públicas: Fotos generadas (2012-2013)

En la asignatura Patrimonio Fotográfico del Máster en Patrimonio Audiovisual de la Facultad de Ciencias de la Información se produjeron 20 fotos para 6 términos, con una participación de 5 alumnos y por tanto una media de 4 fotos por autor. El término con mayor número de imágenes fue "Tecnología" (5) y el de menor fue "Primavera" (Tabla XIV).

\begin{tabular}{|c|c|}
\hline Concepto & Fotos \\
\hline 001-Tecnología & 5 \\
\hline 002-Urbanismo & 4 \\
\hline 003-Depresión & 3 \\
\hline 004-Contaminación & 3 \\
\hline 005-Tráfico & 3 \\
\hline 006-Primavera & 2 \\
\hline Total & 20 \\
\hline
\end{tabular}

Tabla XIV. Patrimonio Fotográfico: Fotografías generadas (2012-2013)

\begin{tabular}{lr}
\hline Concepto & Fotos \\
\hline 001-Archivo & 16 \\
\hline 002-Colección & 21 \\
\hline 003-Contenido & 7 \\
\hline 004-Contexto & 11 \\
\hline 005-Organicidad & 11 \\
\hline 006-Normalización & 8 \\
\hline 007-Titularidad & 9 \\
\hline 008-Original & 10 \\
\hline Total & 93 \\
\hline
\end{tabular}

Tabla XV. Tópicos especiais em Organizaçao da Informação: Fotos generadas (2012-2013)

En esta segunda fase se llevó a cabo una experiencia de gran interés para el proyecto, con los alumnos de la asignatura de posgrado de "Tópicos especiais em Organizaçao da Informaçao. Acervos fotográficos" de la Facultad de Ciência da Informação de la Universidade de Brasilia. Se propusieron 8 términos de los que resultaron un total de 93 imágenes, con la participación de 7 alumnos y una media de 13,2 fotos por autor (Tabla XV).

\subsection{Tercera fase (2013-2014)}

La tercera fase solo se desarrolló en un cuatrimestre y participaron 53 alumnos de dos asignaturas: Documentación Fotográfica (Grado: Grupos A y B), y Documentación Iconográfica. Se seleccionaron 10 conceptos para los dos grupos de Fotográfica, y los 6 primeros de la relación fueron los mismos aplicados en Iconográfica. El resultado fue de 439 imágenes con una media de 8,3 por autor (Tabla XVI).

\begin{tabular}{lrr}
\hline Asignaturas & Autores & Fotos \\
\hline Documentación Fotográfica A & 31 & 284 \\
\hline Documentación Fotográfica B & 17 & 129 \\
\hline Documentación Iconográfica & 5 & 26 \\
\hline Total & 53 & 439 \\
\hline
\end{tabular}

Tabla XVI. Fotografías creadas (2013-2014)

En la asignatura Documentación Fotográfica (Grado) la participación fue masiva, con una media de 9,2 fotografías por alumno en el primer grupo y de 7,58 en el segundo. El mayor número de fotos fue para el término "Reciclar" con 48 , y el menos número de fotos fue para "Vejez" con 34 (Tabla XVII).

\begin{tabular}{lrrr}
\hline Conceptos & Grupo A & Grupo B & Total \\
\hline 001-Reciclar & 31 & 17 & 48 \\
\hline 002-Compromiso & 29 & 14 & 43 \\
\hline 003-Formación & 30 & 14 & 44 \\
\hline 004-Inmigración & 30 & 13 & 43 \\
\hline 005-Infancia & 30 & 13 & 43 \\
\hline 006-Riesgo & 29 & 13 & 42 \\
\hline 007-Gente & 28 & 12 & 40 \\
\hline 008-Vacaciones & 28 & 11 & 39 \\
\hline 009-Exilio & 26 & 11 & 37 \\
\hline 010-Vejez & 23 & 11 & 34 \\
\hline Total & 284 & 129 & 413 \\
\hline
\end{tabular}

Tabla XVII. Documentación Fotográfica: Fotos generadas (2012-2013)

\begin{tabular}{lr}
\hline Conceptos & Fotos \\
\hline 001-Reciclar & 4 \\
\hline 002-Compromiso & 4 \\
\hline 003-Formación & 4 \\
\hline 004-Inmigración & 5 \\
\hline 005-Infancia & 5 \\
\hline 006-Riesgo & 4 \\
\hline Total & 26 \\
\hline
\end{tabular}

Tabla XVIII. Documentación Iconográfica: Fotos generadas (2012-2013) 
En la asignatura Documentación Iconográfica (Máster) participaron 5 alumnos en la especialidad en Medios de Comunicación, con una media de 5,2 fotos. En este caso la respuesta fue similar con 5 fotos para los conceptos "Inmigración" e "Infancia", y cuatro para el resto (Tabla XVIII).

\section{Conclusiones}

La aportación de nuevos métodos docentes es imprescindible en estos momentos, ya que los sistemas tradicionales resultan inadecuados para el aprendizaje. Sistemas como el modelo que se presenta contribuye al desarrollo de los programas de Innovación Docente, y al desarrollo de los objetivos generales y específicos del Espacio Europeo de Educación Superior, sobre todo en los aspectos referidos a la participación y motivación de los alumnos.

Es este sentido se ha comprobado que el uso de la fotografía en la docencia despierta el interés de los alumnos (258 participantes de 15 asignaturas), fomenta su participación en el aula y fuera de ella, la interacción entre los estudiantes, y el intercambio de ideas a la vez que estimula el debate.

Es importante señalar que no se trata tan solo de aportaciones teóricas sino que como consecuencia del trabajo realizado se ha generado un banco de imágenes fotográficas de calidad, dispuesto para su uso no comercial y libre de derechos de autor. Esta fototeca, compuesta por más de 2.300 fotografías, forma parte del patrimonio digital de la Universidad Complutense de Madrid.

La UCM se involucra, con la Facultad de Ciencias de la Documentación como primer centro experimental, en la investigación en materia de Documentación Fotográfica, que sin duda necesita ser desarrollada en otros centros universitarios españoles y con una visión más amplia.

Esta experiencia, además de formar a los estudiantes en la creación y lectura de las fotografías, así como en su análisis documental, abre una vía de estudio en cuanto a la relación imagen-texto, gracias a la elaboración de los pies de foto literarios que se incluyen en las fichas de trabajo.

\section{Referencias}

Britsch, Susan (2010). Photo Booklets for English Language Learning: Incorporating Visual Communication into Early Childhood Teacher Preparation // Early Childhood Education Journal, 38:3, 171-177.

Casajús, Concha; Diéguez, Silvia; Pena, Carmen (2008). El arte reproducido. Fotografías de la colección Lafuente Ferrari. Madrid: Edición de las autoras.

García Marco, Francisco Javier (2013). Educación y aprendizaje de la información y la documentación // El Profesional de la Información. 22:6, 489-504.

López del Ramo, Joaquín (2008). Calidad e Innovación Docente en el Marco de la Convergencia Europea. Madrid: Dykinson.

Moreiro, José Antonio (2014). "Archivos institucionales y docencia sobre imágenes en la Universidad Carlos III de Madrid", en Actas del I Congreso de Documentación Fotográfica. XXIII Jornadas FADOC. Madrid: Facultad de Ciencias de la Documentación de la UCM.

Munakata, Mika; Vaidya, Ashwin (2012). Encouraging Creativity in Mathematics and Science through Photography // Teaching Mathematics and Its Applications: An International Journal of the IMA, 31:3, 121-132.

Olivera Zaldua, María; Sánchez Vigil, Juan Miguel; Marcos Recio, Juan Carlos. (2013). Imaginando. Formación de un banco de imágenes en la UCM para la docencia // Ríos Ortega, Jaime; Ramírez Velázquez, César Augusto (coord.). La Bibliotecología y la Documentación en el contexto de la internacionalización y el acceso abierto. México: Universidad Nacional Autónoma de México. 83102.

Rincón García, Wifredo (2012). Una colección de fotografías de Guillermo Kalho cedida en 1933 por el gobierno de México al profesor Ángulo Íñiguez para sus trabajos de Arte Mexicano // Rincón García, Wifredo; Pascual Chenel, Álvaro (ed.). Argentum, Estudios artísticos en homenaje a Dra. Amelia López-Yarto Elizalde. Zaragoza: Aneto. 101-118.

Sánchez Vigil, Juan Miguel; Marcos Recio, Juan Carlos; Olivera Zaldua, María (2014). Tesis doctorales sobre fotografía en la universidad: Análisis de la producción y dirección (1976-2012) // Revista Española de Documentación Científica. 37:1,

Sánchez Vigil, Juan Miguel; Olivera Zaldua, María; Salvador Benítez, Antonia; Ayala Sorenssen, Federico (2012). Imaginando: uso y aplicaciones de la fotografía en los procesos de aprendizaje. Proyecto de Innovación docente UCM. Madrid: Universidad Complutense.

Sánchez Vigil, Juan Miguel; Salvador Benítez, Antonia (2013). Documentación fotográfica. Barcelona: Universitat Oberta de Catalunya.

Sprinborg, Martin (2013). Teaching and Learning: Visualizing Our Work // Thought \& Action, 29, 141-149.

Enviado: 2014-03-31. Segunda versión: 2014-06-09. Aceptado: 2014-07-10. 


\section{Apéndice: Algunas fotografías seleccionadas}
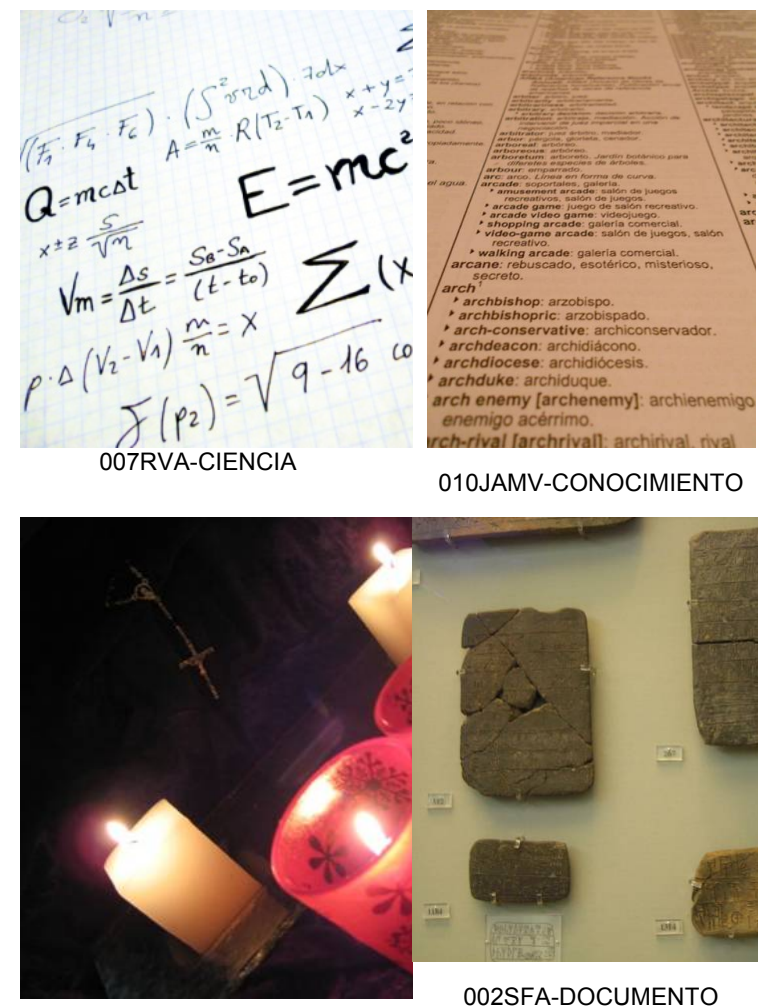

010NJF-DESEO

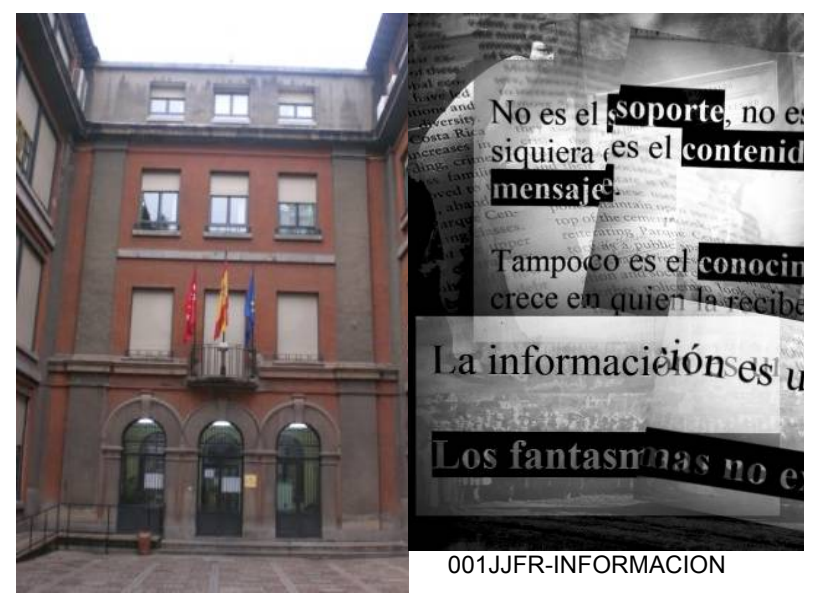

006GAS-ESTRÉS

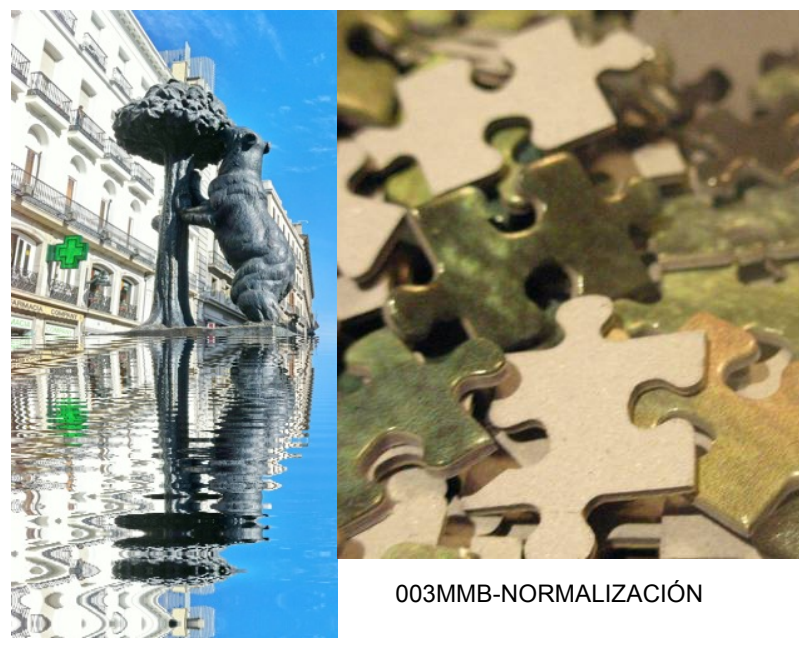

005JCRM-MAGIA

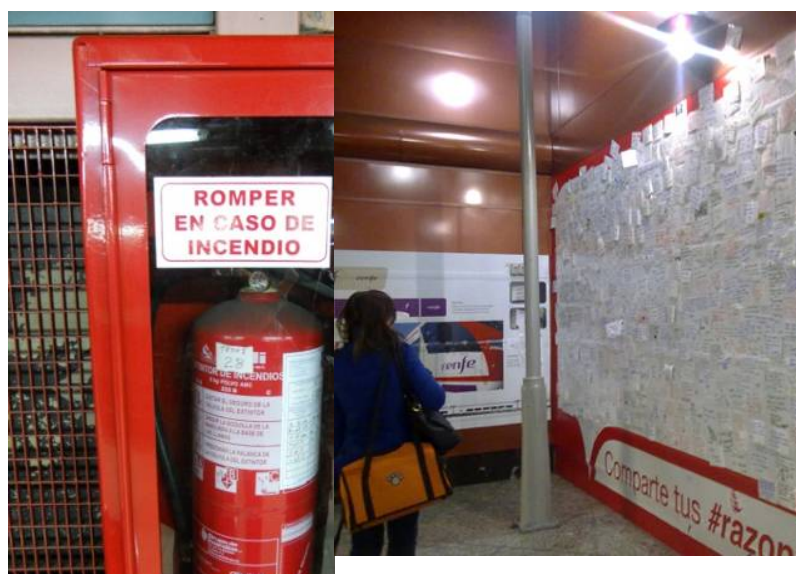

008MPGA-REDES SOCIALES 
